\title{
Desenvolvimento, composição e propriedades bioquímicas do fermentado alcoólico de uvaia (Eugenia pyriformis Cambess)
}

Luciene Lacerda Costa, Luiza Vilela, Maxwel Suzigan Gomide, Pedro Henrique Ferreira Tomé, Edson José Fragiorge, Márcia Arocha Gularte

https://doi.org/10.4322/mp.978-65-991393-5-2.c3

\section{Resumo}

O uso de outras frutas, diferentes da uva, na produção de bebidas fermentadas está se tornando popular no Brasil e representa inovação no consumo. Análises físicoquímicas, avaliação da conformidade com a legislação brasileira para fermentados de frutas e presença de compostos bioativos em bebida fermentada de uvaia, desenvolvida em laboratório, foram investigados. Na fermentação da polpa do fruto foi utilizada a levedura Saccharomyces cerevisiae (Fermentis A Lessaffre Division Safbrew S.33). Sólidos solúveis totais, $\mathrm{pH}$ e acidez total titulável foram monitorados durante vinte e sete dias em esquema fatorial $(10 \times 3)$ com 10 períodos de fermentação e 3 dornas com 3 repetições, totalizando 90 parcelas experimentais. Grau alcoólico, densidade relativa a $20,0^{\circ} \mathrm{C}, \mathrm{pH}$, acidez total titulável, acidez fixa, acidez volátil, sólidos solúveis totais, açúcares redutores, açúcares totais, extrato seco total, extrato seco reduzido, anidrido sulfuroso total, cinzas, fenóis totais, DPPH e taninos, foram quantificados após trinta dias, em um plano experimental avaliado com 3 repetições, em triplicata. Em conclusão, o vinho de uvaia em conformidade com a legislação brasileira, classificado como suave e encorpado, representa fonte de compostos bioativos e fornece elevada atividade antioxidante.

Palavras-chave: fermentação, frutas, Saccharomyces, vinho.

\section{Introdução}

A uvaia é uma fruta de nome científico Eugenia pyriformis Cambess pertencente a família Myrtaceae, típica da Mata Atlântica, ocorre de São Paulo ao Rio Grande do Sul. Seu nome deriva-se do tupi ubaia ou ybá-ia que significa fruto azedo. A árvore tem aproximadamente 6 a 13 metros de altura e geralmente com tronco único ou bifurcado, de no máximo 50 centímetros de diâmetro (MAIOCHI, 2009).

A uvaia apresenta-se como uma pequena baga com aproximadamente quatro centímetros de diâmetro, possui de uma a duas sementes grandes cobertas por polpa aquosa e delicada, de sabor doce ou agridoce, casca fina amarelo-ouro ou amarelo avermelhada, ligeiramente aveludada, assemelhando-se em textura à pele de pêssego, e que quando madura apresenta aroma intenso e agradável (MATTOS, 1988; MAIOCHI, 2009).

A uvaia in natura apresenta a seguinte composição: aproximadamente $93,29 \mathrm{~g}^{100 \mathrm{~g}^{-1}}$ de umidade, 4,6 mg $100 \mathrm{~g}^{-1}$ de acidez em função do ácido cítrico, 4,6 ${ }^{\circ}$ Brix de sólidos 
solúveis totais (SGANZERLA et al., 2018), 76,31 $\mathrm{mg} 100 \mathrm{~g}^{-1}$ de vitamina C (COUTINHO; PASCOLATTI; MOREIRA, 2016).

Os frutos da uvaia podem ser consumidos na forma de sucos, geleias e doce (SGANZERLA et al., 2018). Porém, a conservação pós-colheita é complicada devido à sensibilidade ao toque e a capacidade fermentativa (MAIOCHI, 2009). Pequenas modificações do fruto, estádios de maturidade extremos ou fermentações são fatores de rejeição pelo consumidor (ROSA et al., 2018). Neste contexto, o desenvolvimento de novos produtos é interessante para ampliar e diversificar o consumo diminuindo as perdas pós-colheitas.

O uso de outras frutas, além da uva, na produção de bebidas fermentadas é comum em outros países, principalmente na Europa. São utilizadas maçãs, peras, groselhas, framboesas e cerejas (ASSIS NETO et al., 2010). Porém, a tecnologia de obtenção dessas bebidas é bastante distinta, pois depende das características de cada fruto. Há consenso em relação ao uso de levedura, temperatura ideal de fermentação e necessidade de tratamento da fruta escolhida e do mosto (DIAS; SCHWAN; LIMA, 2003).

Fermentado de fruta é a bebida com graduação alcoólica de quatro a quatorze por cento em volume, a vinte graus Celsius, obtida da fermentação alcoólica do mosto de fruta sã, fresca e madura e que pode conter ingredientes opcionais como açúcar e água (BRASIL, 2009). Segundo Batista, Fragiorge e Tomé (2019) a fermentação alcoólica ocorre a partir do consumo de sacarose por ação de uma levedura, que pode estar naturalmente presente no alimento ou adicionada artificialmente, produzindo gás carbônico, etanol e outros compostos.

Antioxidantes são substâncias presentes em baixas concentrações quando comparada ao substrato oxidável, atrasam ou inibem a oxidação desse substrato de maneira eficaz, exibem capacidade de eliminação de radicais livres e por quelantes de íons metálicos, protegendo assim os tecidos de danos oxidativos (BOHN et al., 2015) e na prevenção de doenças crônicas degenerativas por apresentar altos níveis de

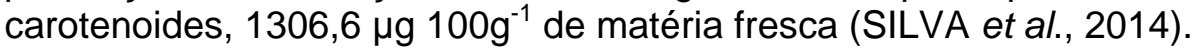

Os polifenóis totais são os principais responsáveis pela atividade antioxidante em frutos (Sun et al., 2002). Sucos e fermentados, do ponto de vista tecnológico, os compostos fenólicos podem interferir nas características sensoriais do produto final como cor, sabores amargos, adstringentes, aromas e claridade (ZARDO et al., 2009).

Os teores de taninos no vinho são influenciados pela duração da maceração (SMITH; MCRAE; BINDON, 2015), pela temperatura, volume de líquido remontado e número de remontagens por unidade de tempo (RIZZON; DALL'AGNOL, 2007). Por processos de oxirredução, os taninos contribuem na determinação da cor dos vinhos (GARCíAESTÉVEZ et al., 2017) e atividade antioxidante (OLEJAR et al., 2019).

O presente estudo teve como objetivos desenvolver uma bebida fermentada de uvaia, avaliar se a mesma está em conformidade com a legislação brasileira para fermentados de frutas e verificar a presença de compostos bioativos.

\section{Materiais e Métodos}

\subsection{Local do experimento}

Os frutos de uvaia foram cedidos pelo Instituto Federal de Educação, Ciência e Tecnologia do Triângulo Mineiro - IFTM < http://isni.org/isni/0000000403704193>, 
Campus Uberaba, localizado no município de Uberaba - MG, situado a $19^{\circ} 39^{\prime}$ $19^{\prime \prime}$ S e $47^{\circ} 57^{\prime} 27^{\prime \prime} \mathrm{W}$, altitude de $795 \mathrm{~m}$. De acordo com a classificação climática de Köppen-Geiger o clima é classificado como Aw e a temperatura média anual é 21,5 ${ }^{\circ} \mathrm{C}$ e pluviosidade média anual de $1479 \mathrm{~mm}$ (ALVARES et al., 2013). Os frutos foram colhidos de 5 uvaieiras, implantadas em espaçamento de $4 \mathrm{~m} \times 3,5 \mathrm{~m}$, no pomar da Instituição. Os frutos foram coletados manualmente nas primeiras horas do dia, de maneira cuidadosa, evitando danos físicos ao produto. Os frutos de uvaia se apresentavam no estádio de maturação definido com base na coloração da casca amarela e em padrões estabelecidos empiricamente pelos consumidores que considera no ponto de consumo. O material foi transportado até o setor de Agroindústria do IFTM - Campus Uberaba, por meio de sacos stomacher em caixas isotérmicas $\left(5,0^{\circ} \mathrm{C} \pm 0,5^{\circ} \mathrm{C}\right)$, com gelo reutilizável rígido Gelo-x (Termogel $\left.{ }^{\circledR}\right)$. Os frutos que apresentavam injúrias nas superfícies e com partes atacadas por insetos e suas larvas foram descartados. Utilizou-se os frutos maduros sem suas sementes, os quais, foram higienizados e sanitizados em água clorada, cloro ativo 2,5\% (Start ${ }^{\circledR}$ ) L. 442353, a $200,0 \mathrm{mg} \mathrm{L}^{-1}$ por 15 minutos de contato e, em seguida, foram submetidos a tríplice lavagem em água destilada estéril. Logo após, foram congelados a $-18,0{ }^{\circ} \mathrm{C}$ até $\mathrm{o}$ processamento e realização da caracterização físico-química. As análises físicoquímicas foram realizadas no Laboratório de Bromatologia localizados no IFTM Campus Uberaba.

\subsection{Caracterização físico-química dos frutos de uvaia}

Foram caracterizadas três amostras aleatórias de frutos de uvaia e avaliados quanto ao teor de sólidos solúveis ('Brix), determinado por refratômetria (refratômetro portátil Reichert ${ }^{\circledR}$ AR200); acidez total titulável, obtida por meio da titulação de $10 \mathrm{~g}$ de polpa homogeneizada e diluída para $100 \mathrm{~mL}$ de água destilada, com solução padronizada de hidróxido de sódio a $0,1 \mathrm{~mol} \mathrm{~L}^{-1}$ expressa em porcentagem de ácido cítrico (Silva; Queiroz, 2002) e $\mathrm{pH}$, medido diretamente na polpa homogeneizada, utilizando-se o potenciômetro de bancada digital (TEKNA ${ }^{\circledR}$ T1000).

\subsection{Processamento do fermentado de uvaia}

Frutos inteiros foram despolpados em despolpadeira industrial (Itametal ${ }^{\circledR} 0,25$ DF). Realizou-se a diluição da polpa de uvaia na proporção de $750 \mathrm{~g}$ para seis litros de água deionizada estéril. A chaptalização foi realizada adicionando sacarose até atingir 26,0 ${ }^{\circ}$ Brix. Em seguida, foi feita a sulfitação usando bisulfito de sódio e pasteurização lenta $\left(65,0^{\circ} \mathrm{C}\right.$ por 30 minutos). Realizou-se a correção do pH à 4,0 com carbonato de sódio.

A levedura utilizada foi a Saccharomyces cerevisiae (Fermentis A Lessaffre Division Safbrew S.33), liofilizada, com viabilidade celular de 97,0\%, livre de OGMs (Organismos Geneticamente Modificados) e Glúten. Inoculou-se a levedura no volume de $100,0 \mathrm{~mL}$, concentração de $0,38 \mathrm{~g} \mathrm{~L}^{-1}$, conforme indicação do fabricante constituindo etapa denominada pé-de-cuba. Posteriormente, transferiu-se para 0 volume seguinte integralizando $1000 \mathrm{~mL}$ e este último inoculado na dorna principal. O intervalo entre os volumes foi de $24 \mathrm{~h}$.

O experimento foi conduzido em sala refrigerada com ar condicionado ajustado para $24{ }^{\circ} \mathrm{C}$ conforme instruções do fabricante da levedura de temperatura ideal para fermentação, até que o mosto apresentou 12,08 ${ }^{\circ}$ Brix (27 dias). Durante o período de fermentação, foram realizadas análises físico-químicas a cada três dias de sólidos solúveis totais ( $\left.{ }^{\circ} \mathrm{Brix}\right), \mathrm{pH}$ e acidez total $\left(\mathrm{meq} \mathrm{L}^{-1}\right)$. 
O fermentado alcoólico foi transferido por sifonação seguida de filtração em peneira $\left(\right.$ Paganini $^{\circledR}$ ) apresentando malha de $28 / 30 \mathrm{MPL}$ (malhas por polegada linear) ou 0,55 $\mathrm{mm}$ e bitola do fio, 32 BWG (Birmighan Wire Gauge) ou 0,22 $\mathrm{mm}$. O filtrado foi envasado em garrafas de vidro tipo âmbar de $250,0 \mathrm{~mL}$ previamente higienizadas e sanitizadas.

A fermentação foi interrompida por pasteurização lenta $\left(65,0^{\circ} \mathrm{C}\right.$ por 30 minutos). $\mathrm{O}$ conteúdo foi lacrado com rolhas de cortiça. Posteriormente, as garrafas foram armazenadas em posição horizontal em câmara fria a $5,0^{\circ} \mathrm{C} \pm 0,4^{\circ} \mathrm{C}$, umidade relativa de $40,0 \% \pm 1,0 \%$ durante um mês para concluir o envelhecimento das bebidas.

\subsection{Caracterização físico-química do fermentado de uvaia pós-envelhecimento}

O fermentado, após período de envelhecimento de um mês foi analisado quanto ao grau alcoólico $\left({ }^{\circ} \mathrm{GL}\right)$, densidade $\left(\mathrm{g} \mathrm{mL}^{-1}\right)$ corrigida a $20,0{ }^{\circ} \mathrm{C}, \mathrm{pH}$, acidez total titulável (meq $\mathrm{L}^{-1}$ ), acidez fixa (meq $\mathrm{L}^{-1}$ ), acidez volátil (meq $\mathrm{L}^{-1}$ ), sólidos solúveis totais ( ${ }^{\circ} \mathrm{Brix}$ ), açúcares totais $\left(\mathrm{g} \mathrm{L}^{-1}\right)$, açúcares redutores em glicose $\left(\mathrm{g} \mathrm{L}^{-1}\right)$, extrato seco a $100^{\circ} \mathrm{C}(\mathrm{g}$ $\left.\mathrm{L}^{-1}\right)$, extrato seco reduzido $\left(\mathrm{g} \mathrm{L}^{-1}\right)$, cinzas $\left(\mathrm{g} \mathrm{L}^{-1}\right)$ conforme Instituto Adolfo Lutz (IAL, 2008) e em conformidade com a Instrução Normativa $n^{\circ} 34$ de 29 de novembro de 2012 do Ministério da Agricultura, Pecuária e Abastecimento (BRASIL, 2012).

Além das análises exigidas pela legislação foram realizadas análises complementares de atividade antioxidante, polifenóis totais e taninos.

A determinação da atividade antioxidante por meio do método de sequestro de radicais livres DPPH (2,2-Diphenyl-1-picrylhydrazyl), avalia a capacidade antioxidante em doar átomos de hidrogênio ou elétrons para o radical DPPH com consequente mudança de coloração roxa para amarela (BRAND-WILLIAMS; CUVELIER; BERSET, 1995). Para tanto, uma solução estoque de DPPH $40 \mu \mathrm{g} \mathrm{mL}^{-1}$, foi preparada e as amostras de bebida fermentada foram diluídas na proporção de 1:10 em metanol. Em tubos de ensaio $0,1 \mathrm{~mL}$ de amostra diluída foi adicionada a 3,9 $\mathrm{mL}$ de solução estoque de DPPH. Um tubo controle contendo 0,1 de metanol e 3,9 mL de solução estoque de DPPH foi preparado e como branco o metanol foi utilizado. Os tubos ficaram em repouso no escuro por $30 \mathrm{~min}$ e, em seguida, a leitura a $517 \mathrm{~nm}$ em espectrofotômetro, foi realizada (GEHAKA ${ }^{\circledR}$ UV-380G). A equação 1 foi utilizada para o cálculo da atividade antioxidante.

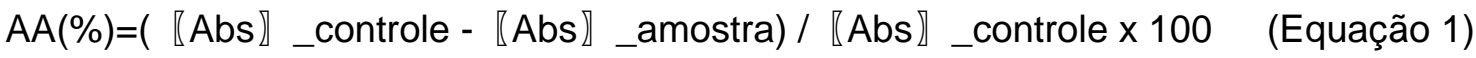

$\mathrm{Na}$ determinação de polifenóis totais, foi utilizado o método de Singleton e Rossi (1965), adaptado. As amostras de bebida fermentada foram diluídas na proporção de 1:10 em metanol. Uma curva de calibração foi construída utilizando ácido gálico como padrão nas proporções de $0,50,100,150,250,500 \mathrm{mg} \mathrm{L}^{-1}$. Em tubos de ensaio foi dissolvido $0,5 \mathrm{~mL}$ de fermentado em $2,5 \mathrm{~mL}$ do reagente de Folin-Ciocalteau diluído na proporção de 1:10 em água e 2,0 mL de carbonato de sódio 7,5\%. Os tubos ficaram em repouso no escuro por duas horas e, em seguida, o conteúdo dos tubos foi transferido para cubetas e a leitura em espectrofotômetro em $765 \mathrm{~nm}$ foi realizada. Os resultados foram expressos em mg EAG $\mathrm{L}^{-1}$.

Para determinação de taninos, utilizou-se o método de hidrólise ácida, descrito por Zoecklein et al. (1999) e utilizado por Lins e Sartori (2014). Diluiu-se as amostras na proporção de 1:50 em água deionizada. Adicionou-se a dois tubos de ensaio, previamente identificados de forma distinta (A e B), $4 \mathrm{~mL}$ de fermentado diluído, $2 \mathrm{~mL}$ de água e $6 \mathrm{~mL}$ de $\mathrm{HCl} 12 \mathrm{~mol} \mathrm{~L}^{-1}$. Os tubos $A$ foram levados a banho-maria a $100{ }^{\circ} \mathrm{C}$ por 30 minutos e após resfriamento adicionou-se $1 \mathrm{~mL}$ de etanol a $95 \%$. Os tubos $\mathrm{B}$ 
ficaram em repouso à temperatura ambiente. Posteriormente, realizou-se leitura em espectrofotômetro a $550 \mathrm{~nm}$ usando a água deionizada como branco. O teor de taninos foi calculado empregando-se a equação 2.

$$
\operatorname{TN}\left(g^{-1}\right)=19,33 \times \Delta
$$

Sendo, $\Delta$ a diferença entre as absorbâncias dos tubos $\mathrm{A}$ e B de cada amostra.

\subsection{Delineamento experimental no mosto}

O período de fermentação foi avaliado em um delineamento estatístico, em esquema fatorial $(10 \times 3)$ com 10 períodos de fermentação e 3 dornas com 3 repetições, totalizando 90 parcelas experimentais.

\subsection{Delineamento experimental no fermentado}

O fermentado obtido (vinho) foi conduzido em um plano experimental avaliado com 3 repetições, em triplicata.

\subsection{Análise estatística}

Os resultados dos parâmetros das análises físico-químicas do vinho foram expressos em médias e seus desvios-padrões. Médias e desvios-padrões foram realizados utilizando o programa estatístico SISVAR (FERREIRA, 2011).

\section{Resultados e Discussão}

\subsection{Caracterização físico-química dos frutos de uvaia}

A polpa do fruto de uvaia apresentou teor de sólidos solúveis totais de 5,87 ${ }^{\circ}$ Brix, acidez total titulável de $2,13 \mathrm{~g} 100 \mathrm{~g}^{-1}$ ácido cítrico e $\mathrm{pH}$ de 2,86. Outros pesquisadores que trabalharam na caracterização físico-química da uvaia obtiveram valores divergentes deste estudo, principalmente quanto aos sólidos solúveis e acidez, Sganzerla et al. (2018), sólidos solúveis, 4,6 ${ }^{\circ}$ Brix, acidez de 0,75 mg $100 \mathrm{~g}^{-1}$ ácido cítrico e pH de 3,45; Silva et al. (2018), sólidos solúveis, 7,75 ${ }^{\circ}$ Brix a 10,50 ${ }^{\circ}$ Brix, acidez de 1,63 g $100 \mathrm{~g}^{-1}$ ácido cítrico a 1,67 g $100 \mathrm{~g}^{-1}$ ácido cítrico e pH de 3,06 a 2,96 (frutos grandes a frutos pequenos) e Chaves Neto, Silva e Dantas (2020), média de sólidos solúveis, 8,34 ${ }^{\circ}$ Brix, acidez de 3,44 g $100 \mathrm{~g}^{-1}$ ácido cítrico e pH 3,0 (frutos

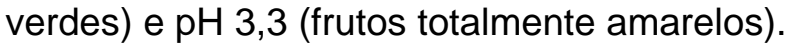

\subsection{Caracterização do fermentado de uvaia pós-envelhecimento}

Os resultados dos valores de sólidos solúveis totais ('Brix) durante o período de fermentação do mosto de uvaia são apresentados na Figura 1.

Houve uma redução linear, 25,92 ${ }^{\circ}$ Brix para $12,08{ }^{\circ}$ Brix, com um coeficiente de determinação de $92,37 \%$, no teor de sólidos solúveis totais durante o período de fermentação. O consumo de açúcares do mosto é feito por leveduras que convertem açúcar em etanol. A não conversão total dos açúcares em álcool foi observada por Corazza, Rodrigues e Nozaki (2001), que encontraram valor de 8,0 ${ }^{\circ}$ Brix para fermentado de laranja e atribuem este resultado à presença de açúcares não fermentescíveis no suco de laranja.

Os resultados do comportamento dos parâmetros de acidez total titulável e pH durante o período de fermentação do mosto de uvaia são apresentados na Figura 2. 


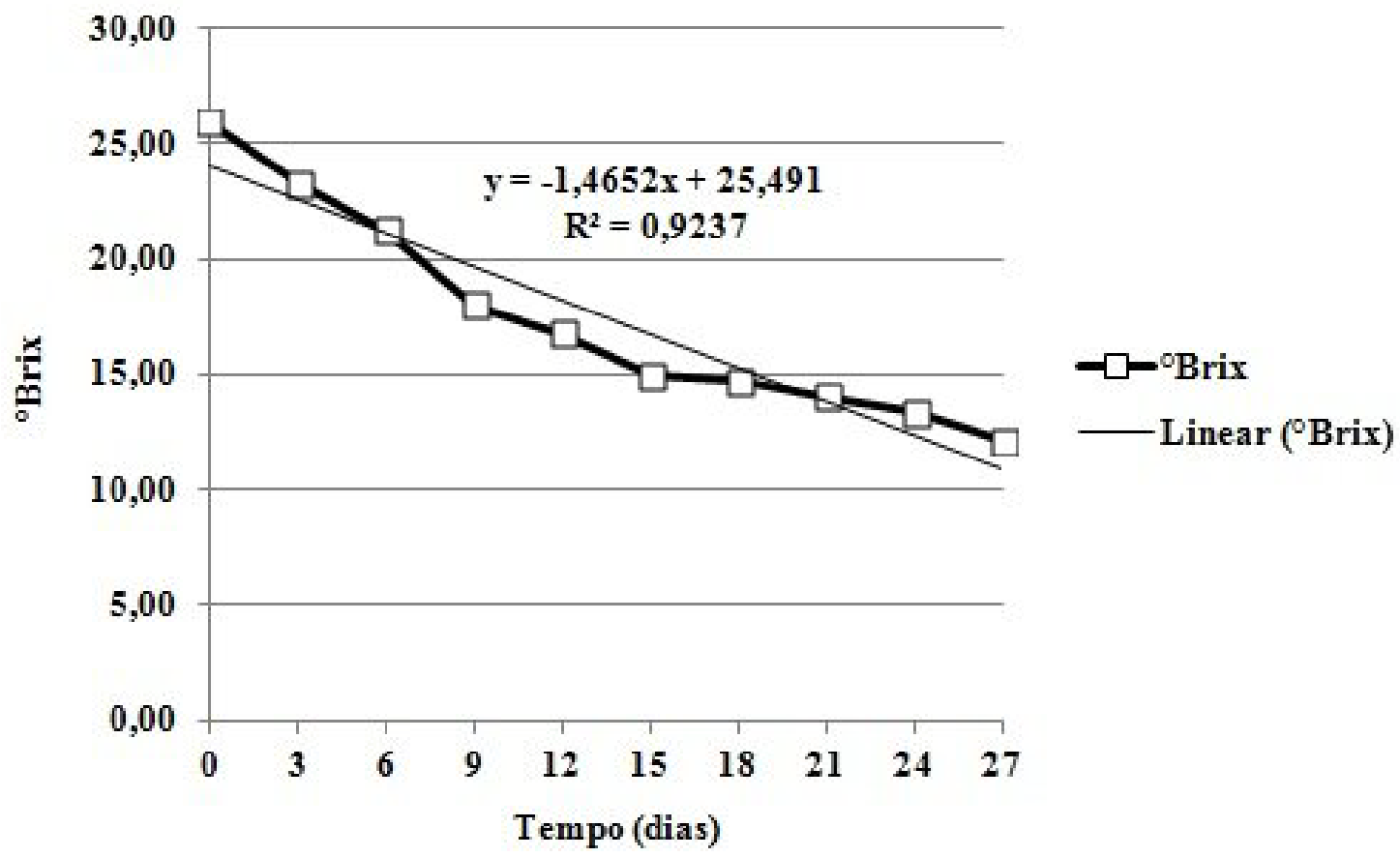

Figura 1. Valores de ${ }^{\circ}$ Brix do mosto de uvaia (Eugenia pyriformis Cambess), durante o período de fermentação (27 dias) em temperatura média de $24,0^{\circ} \mathrm{C} \pm 1,0{ }^{\circ} \mathrm{C}$.

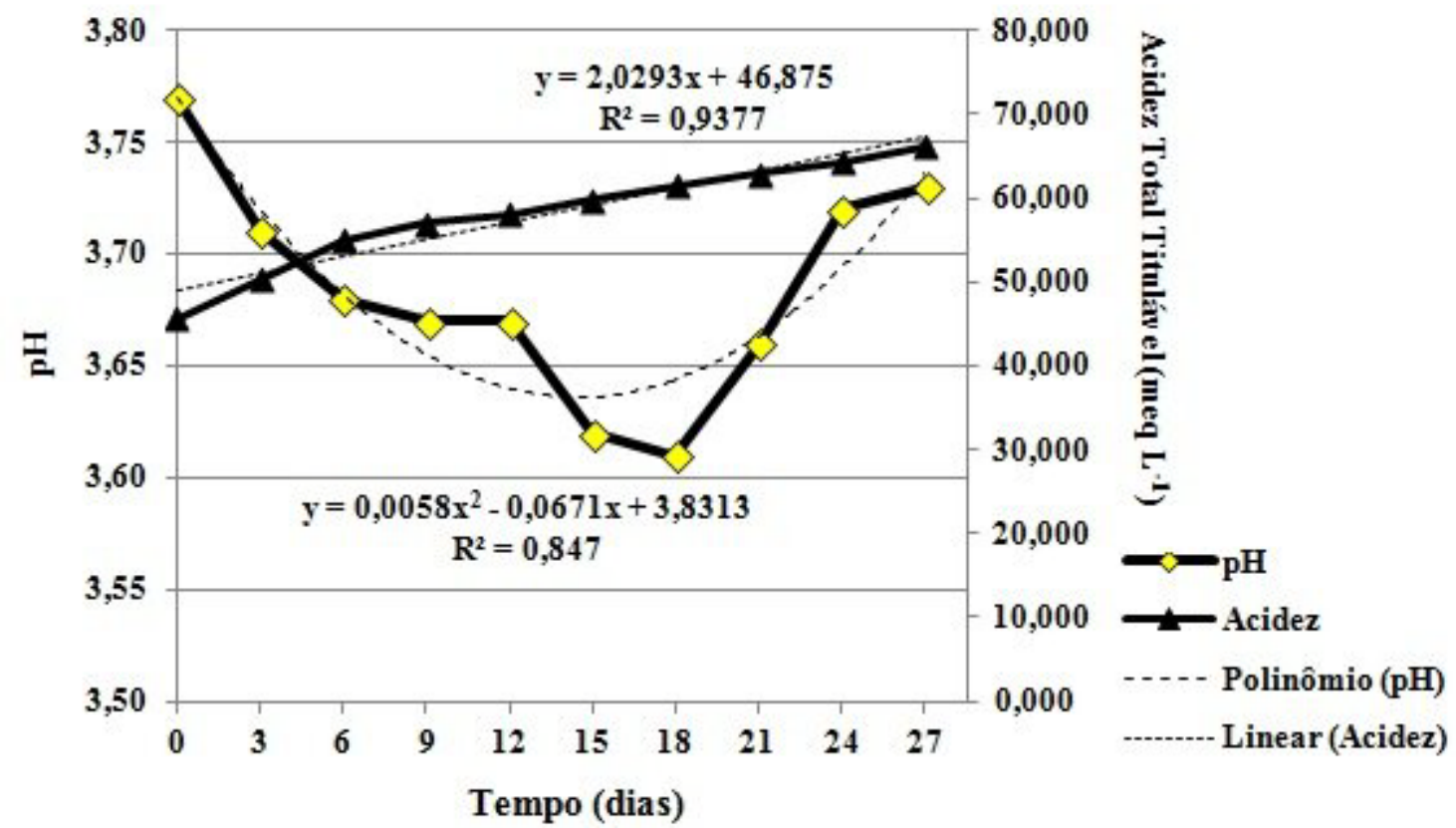

Figura 2. Relação entre os valores de pH e acidez total titulável do mosto de uvaia (Eugenia pyriformis Cambess), durante o período de fermentação (27 dias) em temperatura média de $24,0^{\circ} \mathrm{C} \pm 1,0^{\circ} \mathrm{C}$.

Um modelo de ajuste de curva polinominal na ordem 2 e seu respectivo coeficiente de determinação de $84,70 \%$, foram obtidos na expressão dos valores de $\mathrm{pH}$ que apresentaram queda até o $18^{\circ}$ dia, 3,77 para 3,61, a partir daí, houve aumento até $27^{\circ}$ 
dia, 3,73. Os valores de acidez total titulável apresentaram aumento gradativo, 45,680 $\mathrm{mEq} \mathrm{L}^{-1}$ para $66,070 \mathrm{mEq} \mathrm{L}^{-1}$, com coeficiente de determinação em 93,77\%.

Segundo Borzani et al. (1983) a produção de ácidos orgânicos, tais como ácido lático, acético e succínico, induz o aumento de acidez total titulável e redução de $\mathrm{pH}$ durante o processo de fermentação. Almeida et al. (2006) verificaram variações de pH e acidez total durante o processo fermentativo. Rizzon, Zanus e Manfredini (1994) refere-se à variação da acidez durante a fermentação como interferente para a estabilidade e coloração de bebidas fermentadas.

Os resultados da caracterização físico-química do fermentado de uvaia são apresentados na Tabela 1.

Tabela 1. Resultados obtidos das análises físico-químicas da bebida fermentada alcoólica de uvaia (Eugenia pyriformis Cambess) após o período de maturação (1 mês), em temperatura média de $5,0^{\circ} \mathrm{C}\left( \pm 0,4^{\circ} \mathrm{C}\right)$, umidade relativa de $40,0 \% \pm 1,0 \%$.

\begin{tabular}{|c|c|c|c|c|}
\hline \multirow{2}{*}{ Análise } & \multirow{2}{*}{ Média } & \multirow{2}{*}{$\begin{array}{c}\text { Desvio } \\
\text { Padrão ( } \pm \text { ) }\end{array}$} & \multicolumn{2}{|c|}{ Legislação* } \\
\hline & & & Mínimo & Máximo \\
\hline Grau Alcoólico (ํL) & 11,95 & 0,98 & 4,0 & 14,0 \\
\hline Densidade relativa a $20^{\circ} \mathrm{C}\left(\mathrm{g} \mathrm{L}^{-1}\right)$ & 1,01 & 0,01 & - & - \\
\hline $\mathrm{pH}$ & 3,88 & 0,09 & - & - \\
\hline Acidez total titulável $\left(\mathrm{meq} \mathrm{L}{ }^{-1}\right)$ & 53,780 & 0,40 & 50,0 & 130,0 \\
\hline Acidez fixa $\left(\right.$ meq $\left.L^{-1}\right)$ & 45,050 & 0,89 & 30,0 & - \\
\hline Acidez volátil (meq L ${ }^{-1}$ ) & 8,730 & 0,52 & - & 20,0 \\
\hline Sólidos solúveis totais ( ${ }^{\circ}$ Brix) & 12,03 & 0,55 & - & 30,0 \\
\hline Açúcares redutores $\left(\mathrm{g} \mathrm{L}^{-1}\right)$ & 2,88 & 0,08 & - & - \\
\hline Açúcares totais $\left(\mathrm{g} \mathrm{L}^{-1}\right)$ & 2,4089 & 0,07 & $>3$ (suav & $\leq 3(\operatorname{Seco})$ \\
\hline Extrato seco total $\left(\mathrm{g} \mathrm{L}^{-1}\right)$ & 132,1400 & 0,85 & - & - \\
\hline Extrato seco reduzido $\left(\mathrm{g} \mathrm{L}^{-1}\right)$ & 130,7311 & - & 12 & - \\
\hline Anidrido sulfuroso total $\left(\mathrm{g} \mathrm{L}^{-1}\right)$ & 0,0096 & - & - & 0,35 \\
\hline Cinzas $\left(\mathrm{g} \mathrm{L}^{-1}\right)$ & 1,15 & 0,17 & - & - \\
\hline Fenóis totais (mg EAG L L ${ }^{-1}$ ) & 142,96 & 0,95 & - & - \\
\hline DPPH (\%AA) & 79,34 & 0,88 & - & - \\
\hline Taninos $\left(\mathrm{g} \mathrm{L}^{-1}\right)$ & 0,14 & 0,01 & - & - \\
\hline
\end{tabular}

Resultados dados em (-) = Sem parâmetros para comparação.

*Brasil (2012).

O grau alcoólico de $11,95^{\circ} \mathrm{GL}$, apresentado pelo fermentado de uvaia, está de acordo com o preconizado pela legislação brasileira para vinhos de mesa (BRASIL, 2012), mostrando que o período do processo fermentativo foi suficientemente adequado para a elaboração de álcool em teores próprios de vinhos.

Segundo Vogt (1972) quando um vinho apresentar maior teor de açúcar, menor será o grau alcoólico e consequentemente a densidade será maior que $1,0 \mathrm{~g} \mathrm{~L}^{-1}$. Já os vinhos fermentados por completo apresentam menor teor de açúcar e densidade em torno de $1,0 \mathrm{~g} \mathrm{~L}^{-1}$. A densidade do fermentado de uvaia, 1,01 $\mathrm{g} \mathrm{L}^{-1}$, ficou próxima à densidade do fermentado de goiaba branca, 1,05 $\mathrm{g} \mathrm{L}^{-1}$ (BATISTA; FRAGIORGE; TOMÉ, 2019), portanto, o processo fermentativo foi satisfatório.

De acordo com Manfroi et al., (2006) vinhos com pH entre 3,1 e 3,6 possuem melhores características sensoriais. Neste estudo foi encontrado pH de 3,88 no final do período 
de envelhecimento. Lima e Ferri (2015) encontram pH de 3,9 para fermentado de acerola sendo o resultado atribuído ao estágio de maturação dos frutos.

A legislação brasileira (BRASIL, 2012), não estabelece limites de $\mathrm{pH}$ para fermentados de frutas. Os fermentados com elevado valor de $\mathrm{pH}$ apresentam menor vida útil em prateleira (RABELO; BRAGA, 2017), além de não favorecer o crescimento das leveduras (GAVA; SILVA; FRIAS, 2008; OLIVEIRA et al., 2012). Vinhos com os maiores valores de $\mathrm{pH}$ apresentaram maiores teores alcoólicos (FRACASSO; FUENTEFRIA; TEIXEIRA, 2009).

O regulamento técnico para a fixação dos padrões de identidade e qualidade para fermentado de fruta determina que a acidez total titulável de uma bebida fermentada deva variar entre 50 a $130 \mathrm{meq} \mathrm{L}^{-1}$ (BRASIL, 2012). A acidez total obtida neste estudo encontra-se em conformidade com o estabelecido pela legislação brasileira. A acidez total em menor concentração possibilita um fermentado com suavidade e aromas complexos (OLIVEIRA et al., 2013).

A acidez fixa do vinho de uvaia foi de $45,050 \mathrm{mEq} \mathrm{L^{-1 }}$, estando de acordo com a legislação brasileira para fermentados de frutas, que preconiza o mínimo de 30,0 mEq $\mathrm{L}^{-1}$ (BRASIL, 2012) e muito abaixo quando comparado aos fermentados de jaca, 94,0 mEq L ${ }^{-1}$ (ASQUIERI; RABELO; SILVA, 2008), jabuticaba, 199,23 $\mathrm{mEq} \mathrm{L}^{-1}$ (CHIARELLI; NOGUEIRA; VENTURINI FILHO, 2005) e kiwi, 107,7 mEq L'-1 (PAZ et al., 2007).

Hashizume (2001) recomenda menor teor de acidez volátil já que teores mais altos indicam alterações microbiológicas. A acidez volátil do vinho obtido da uvaia foi de $8,730 \mathrm{mEq} \mathrm{L^{-1 }}$ e este valor está acima ao obtido no fermentado de cajá, $5,5 \mathrm{mEq} \mathrm{L}^{-1}$ (DIAS; SCHWAN; LIMA, 2003), jaca, 6,0 mEq L-1 (ASQUIERI, RABELO e SILVA, 2008) e de acordo com os limites estabelecidos pela legislação brasileira para fermentados de frutas, 20,0 $\mathrm{mEq} \mathrm{L}^{-1}$ (BRASIL, 2012).

As médias dos sólidos solúveis totais apresentadas pelo fermentado de uvaia, 12,03 'Brix está em conformidade com os limites estabelecidos pela legislação brasileira para fermentados de frutas, 30,0 ${ }^{\circ}$ Brix (BRASIL, 2012), próximo aos valores encontrados no fermentado de baru, 12,9 ${ }^{\circ}$ Brix (RIBEIRO; ASCHERI; ASCHERI, 2011), mas, no fermentado de melancia foi de 6,9 ${ }^{\circ}$ Brix (DUARTE; TOMÉ; FRAGIORGE, 2018), valor este abaixo do encontrado neste trabalho.

Os açúcares redutores em glicose, $2,88 \mathrm{~g} \mathrm{~L}^{-1}$, foi muito abaixo quando comparado aos fermentados de banana prata, 32,4 $\mathrm{g} \mathrm{L}^{-1}$ (ARRUDA et al., 2007) e umbu $38,7 \mathrm{~g} \mathrm{~L}^{-1}$ (CARMO et al., 2012). A legislação brasileira, não estabelece limites de açúcares redutores em glicose para fermentados de frutas (BRASIL, 2012).

O valor médio do parâmetro açúcares totais, 2,4089 $\mathrm{g} \mathrm{L}^{-1}$, está dentro dos limites determinados para vinhos de mesa secos, ou seja, abaixo de $3,0 \mathrm{~g} \mathrm{~L}^{-1}$ (BRASIL, 2012). A legislação brasileira, Brasil (2012), não estabelece teor de extrato seco total para bebida fermentada de fruta. $\mathrm{O}$ alto conteúdo de extrato seco total encontrado neste trabalho, $132,14 \mathrm{~g} \mathrm{~L}^{-1}$, pode estar relacionado à caramelização dos açúcares durante a secagem da amostra ou dos minerais da própria fruta, como sugerido por Asquieri, Rabêlo e Silva (2008) ou ainda pela presença de partes sólidas da fruta devido à maceração prolongada (SILVA et al., 1999).

O extrato seco reduzido é obtido através da diferença do extrato seco total e do açúcar, este diminuído de 1 (quando o teor de sulfato for maior que um este deve ser considerado no cálculo). O resultado é expresso em g L ${ }^{-1}$ (IAL, 2008). 
O fermentado de fruta deve possuir um valor mínimo de $12,0 \mathrm{~g} \mathrm{~L}^{-1}$ de extrato seco reduzido (BRASIL, 2012). O teor de extrato seco reduzido determina o corpo do vinho sendo bebidas com menos de $20,0 \mathrm{~g} \mathrm{~L}^{-1}$ consideradas leves e acima de $25,0 \mathrm{~g} \mathrm{~L}^{-1}$ consideradas encorpadas (HASHIZUME, 2001). Neste trabalho, o teor médio de extrato seco reduzido encontrado, $130,7311 \mathrm{~g} \mathrm{~L}^{-1}$, está dentro dos padrões estabelecidos pela legislação brasileira (BRASIL, 2012), sendo considerada uma bebida encorpada.

O fermentado de uvaia apresentou valor médio de anidrido sulfuroso total (teor de sulfato), 0,0096 $\mathrm{g} \mathrm{L}^{-1}$, valor este que está abaixo do fermentado de jabuticaba, 0,0400 $\mathrm{g} \mathrm{L}^{-1}$ (CHIARELLI; NOGUEIRA; VENTURINI FILHO, 2005) e jaca 0,01584 $\mathrm{g} \mathrm{L}^{-1}$ (ASQUIERI; RABÊLO; SILVA, 2008), mas, em acordo com a legislação brasileira (BRASIL, 2012) que estabelece máximo de $0,35 \mathrm{~g} \mathrm{~L}^{-1} \mathrm{e}$, não faz nenhuma referência à quantidade de $\mathrm{SO}_{2}$ livre permitido nos vinhos, sendo este um critério de cada empresa (RIZZON; ZANUS; MANFREDINI, 1994).

A concentração média de cinzas foi de $1,15 \mathrm{~g} \mathrm{~L}^{-1}$. Normalmente, o valor das cinzas é de aproximadamente $10 \%$ do extrato seco total, que neste caso foi de $1 \%$, confirmando os altos valores de extrato seco total e valores normais para as cinzas.

Coutinho, Pascolatti e Moreira (2014) observaram ação antioxidante em uvaia in natura com inibição significativa de $43,3 \%$ em solução de $10 \%$ de extrato de polpa. Para o fermentado de uvaia deste estudo $(11,1 \%$ de polpa de uvaia) obteve-se ação antioxidante de 79,34\%. A maior atividade antioxidante do fermentado pode ser explicada por diferentes fatores como características próprias da matéria-prima (estádio de maturação, clima, solo, época de colheita entre outros) como pela formação de compostos durante o período de fermentação.

Os valores médios de polifenóis totais neste estudo, 142,96 mg EAG $\mathrm{L}^{-1}$, ficou abaixo do observado por Gonzeli e Sartori (2014) em vinhos tintos artesanais, 851,66 a $3031,50 \mathrm{mg} \mathrm{EAG} \mathrm{L}^{-1}$, Lins e Sartori (2014) em amostras de vinhos tintos produzidos no Estado do Paraná, 1014,5 a 2971,0 mg EAG L-1 e Padilha et al., (2017) em vinhos tintos do sul do Brasil, 2003 a $4036 \mathrm{mg} \mathrm{EAG} \mathrm{L}^{-1}$. Em fermentados de frutas observa-se resultados abaixo dos encontrados em vinhos tintos, no fermentado de kiwi, 498,29 mg EAG L ${ }^{-1}$ (PAZ et al., 2007) e em fermentado de maçã $402 \mathrm{mg} \mathrm{EAG} \mathrm{g} \mathrm{L}^{-1}$ (ZARDO et al., 2009).

Abe et al. (2007) afirmam que em vinhos comuns existe uma proporção direta entre quantidade de polifenóis totais e atividade antioxidante. Neste estudo não foi verificada essa relação, podendo a atividade antioxidante estar relacionada à presença de outros compostos como vitamina C e carotenoides (SCHVAB et al., 2015).

Os teores de taninos são semelhantes em vinhos e em fermentados de frutas. $O$ resultado obtido neste estudo, $0,14 \mathrm{~g} \mathrm{~L}^{-1}$, se difere grandemente quando comparado com o vinho Cabernet Sauvignon que reduziu de 1,86 $\mathrm{g} \mathrm{L}^{-1}$ a $1,29 \mathrm{~g} \mathrm{~L}^{-1}$ após dois anos de envelhecimento (MCRAE et al., 2013) e do fermentado de amora suave, 0,76 g L (PIRES et al., 2016). A baixa concentração neste experimento sugere que o tanino precipitou-se ou degradou-se em pequenos oligômeros em alguma etapa do processamento (CHEYNIER et al., 2006).

\section{Conclusão}

Os resultados obtidos na avaliação físico-química do fermentado de uvaia estão em conformidade com os padrões estabelecidos pela legislação brasileira, sendo o produto classificado como suave e encorpado; a bebida apresentou características 
bioativas, com elevada atividade antioxidante apesar de menores teores de polifenóis totais e taninos se comparada a vinhos de uva.

\section{Referências}

ABE L. T. et al. Compostos fenólicos e capacidade antioxidante de cultivares de uvas Vitis labrusca L. e Vitis vinifera L. Ciência e Tecnologia de Alimentos, v. 27, n. 2, p. 394-400, 2007. https://doi.org/10.1590/S0101-20612007000200032.

ALMEIDA M. M. et al. Cinética da produção do fermentado do fruto do mandacaru. Revista Brasileira de Produtos Agroindustriais, v. 82, n.1, p.35-42, 2006. http://dx.doi.org/10.15871/1517-8595/rbpa.v8n1p35-42.

ALVARES, C.A. et al. Köppen's climate classification map for Brazil. Meteorologische Zeitschrif, v. 22, n.6, p 711-728, 2013. https://dx.doi.org/10.1127/09412948/2013/0507.

ARRUDA A. R. et al. Caracterização físico-química e avaliação sensorial de bebida fermentada alcoólica de banana. Revista Ciência Agronômica, v. 38, n. 4, p. 377384, $2007 . \quad$ Disponível em: http://ccarevista.ufc.br/seer/index.php/ccarevista/article/view/97. Acesso em $27 \mathrm{dez}$ 2020.

ASQUIERI E. R.; RABÊLO M. A. S.; SILVA A. G. M. Fermentado de jaca: estudo das características físico-químicas e sensoriais. Ciência e Tecnologia de Alimentos, v. 28, n. 4, p. 881-887, 2008. http://dx.doi.org/10.1590/S0101-20612008000400018.

ASSIS NETO, E. F. A. et al. Elaboração de bebida alcoólica fermentada de jaca (Artocarpus heterophyllus Lam.). Revista Brasileira de Tecnologia Agroindustrial, v. 4, n. 2, p.186-197, 2010. http://dx.doi.org/10.3895/S1981-36862010000200007.

BATISTA, Â. M.; FRAGIORGE, E. J.; TOMÉ, P. H. F. Desenvolvimento do fermentado alcoólico do fruto goiaba branca (Psidium guajava) cv. Kumagai - Myrtaceae. In: VIERA, V. B.; PIOVESAN, N. (Org.). Inovação em Ciência e Tecnologia de Alimentos. Ponta Grossa: Atena Editora, 2019. p. 121-132. https://doi.org/10.22533/at.ed.00019091013.

BOHN T. et al. Mind the gap-deficits in our knowledge of aspects impacting the bioavailability of phytochemicals and their metabolites-a position paper focusing on carotenoids and polyphenols. Molecular Nutrition \& Food Research, v. 59, n. 7, p. 1307-1323. 2015. https://doi.org/10.1002/mnfr.201400745.

BORZANI, W. et al. Alimentos e bebidas produzidos por fermentação. (Série Biotecnologia, 5). 1 ed. v. 5 São Paulo: Blucher, 1983. 227 p.

BRAND-WILLIAMS W.; CUVELIER M. E.; BERSET C. Use of a free radical method to evaluate antioxidant activity. LWT - Food Science and Technology, v. 28, n. 1, p. 2530, 1995. https://doi.org/10.1016/S0023-6438(95)80008-5.

BRASIL. Ministério da Agricultura, Pecuária e Abastecimento. Decreto n ${ }^{0} 6.871$, de 04 de junho de 2009. Regulamenta a Lei $n^{\circ}$ 8.918, de 14 de julho de 1994, dispõe sobre a padronização, a classificação, o registro, a inspeção, a produção e a fiscalização de bebidas. D.O.U. 05/06/2009, p. 20. Brasília, 2009. 
BRASIL. Instrução Normativa $n^{\circ} 34$, de 29 de novembro de 2012. Complementação dos padrões de identidade e qualidade para bebidas fermentadas. D.O.U. 30/11/2012, n² 231, Seção 1, p. 3. Brasília, 2012.

CARMO S. K. S. et al. Produção e caracterização de fermentado de umbu a partir de sua polpa comercial. Revista Brasileira de Produtos Agroindustriais, v. 14, n.1, p.15-20, 2012. https://doi.org/10.15871/1517-8595/rbpa.v14n1p15-20.

CHAVES NETO J. R.; SILVA, S. M.; DANTAS R. L. Atributos de qualidade, compostos bioativos e atividade antioxidante de frutos de uvaieira durante a maturação. Agrarian, v. 13, n. 49, p. 296-308, 2020. https://doi.org/10.30612/agrarian.v13i49.8684.

CHEYNIER V. et al. Structure and properties of wine pigments and tannins. American Journal of Enology and Viticulture, v. 57, n.3, p. 29805, 2006. Disponível em: https://www.ajevonline.org/content/57/3/298. Acesso em 27 dez 2020.

CHIARELLI R. H. C.; NOGUEIRA A. M. P. VENTURINI FILHO W. G. Fermentados de jabuticaba (Myrciaria cauliflora Berg): processos de produção, características físicoquímicas e rendimento. Brazilian Journal of Food Technology, v. 8, n. 4, p. 277-282, 2005.

CORAZZA M.L.; RODRIGUES D. G.; NOZAKI J. Preparação e caracterização do vinho de laranja. Química Nova, v. 24, n.4, p. 449-452, 2001. https://doi.org/10.1590/S0100-40422001000400004.

COUTINHO A. M.; PASCOLATTI Y. S.; MOREIRA I. C. Caracterização físico-química e análise antioxidante da polpa de uvaia (Eugenia pyriformis Cambess). In: OLIVEIRA A. F.; STORTO L. J. (Org.). Tópicos em Ciências e Tecnologia de Alimentos: Resultados de Pesquisas Acadêmicas - Vol. 1, São Paulo: Blucher, 2016. p. 73-94.

DIAS D. R.; SCHWAN R. F.; LIMA L. C. O. Metodologia para elaboração de fermentado de cajá (Spondias mombin L.). Ciência e Tecnologia de Alimentos, v. 23, n. 3, p. 342-350, 2003. https://doi.org/10.1590/S0101-20612003000300008.

DUARTE L. G. O.; TOMÉ P. H. F.; FRAGIORGE E. J. Desenvolvimento e análises físico-químicas do fermentado alcoólico da polpa de banana nanica (Musa spp.). Revista Científica Semana Acadêmica, v. 132, n. 1, p. 1-33, 2018.

FERREIRA, D. F. Sisvar: a computer statistical analysis system. Ciência e Agrotecnologia, v. 35, n. 6, p.1039-1042, 2011. http://dx.doi.org/10.1590/S141370542011000600001.

FRACASSO D.; FUENTEFRIA A. M.; TEIXEIRA M. L. Avaliação toxicológica e quantificação de agentes antioxidantes em vinhos tintos comercializados no município de Concórdia, Santa Catarina. Revista Brasileira de Produtos Agroindustriais, v. 11, n. 2, p.181-189, 2009. http://dx.doi.org/10.15871/1517-8595/rbpa.v11n2p181-189.

GARCÍA-ESTÉVEZ I. et al. Enological Tannin Effect on Red Wine Color and Pigment Composition and Relevance of the Yeast Fermentation Products. Molecules, v. 22, n. 2046, p. 1-15, 2017. http://dx.doi.org/10.3390/molecules22122046.

GAVA, A. J.; SILVA C. A. B.; FRIAS, J. R. G. Tecnologia em alimentos: princípios e aplicações. São Paulo: Nobel, 2008. p. 89-90, 93-94, 114, 381-382.

GONZELI R. A.; SARTORI G. V. Avaliação do conteúdo fenólico e atividade antioxidante de vinhos tintos artesanais. Revista Brasileira de Produtos 
Agroindustriais, v. 16, n. 2, p.179-186, 2014. http://dx.doi.org/10.15871/15178595/rbpa.v16n2p179-186.

HASHIZUME, Takuo. Tecnologia do vinho. In: BORZANI, Walter et al. (Coords). Biotecnologia na Produção de Alimentos. 1 ed. São Paulo: Blucher, 2001. 544p.

IAL, Instituto Adolfo Lutz. Métodos físico-químicos para análise de alimentos. ZENEBON, Odair et al. (Coords). São Paulo: Instituto Adolfo Lutz, 2008. 1020 p.

LIMA L. S.; FERRI V. C. Fermentado de acerola (Malpigiae marginata) monitorado em seu conteúdo de vitamina C. In: $5^{\circ}$ Simpósio de Segurança Alimentar, 2015, Bento Gonçalves. Anais... 5 Simpósio de Segurança Alimentar, Bento Gonçalves-RS. 2015.

LINS A. R.; SARTORI G. V. Qualidade fenólica e atividade antioxidante de vinhos tintos produzidos no estado do Paraná. Revista Brasileira de Produtos Agroindustriais, v. 16, n. 1, p. 69-76, 2014. http://dx.doi.org/10.15871/15178595/rbpa.v16n1p69-76.

MAIOCHI, G. M. Uvaia. Super dose de vitamina C. 2009. Disponível em: $<$ https://apremavi.org.br/uvaia-super-dose-de-vitamina-c/>. Acessado em: 29 de outubro de 2020.

MANFROI, L. et al. Composição físico-química do vinho Cabernet Franc proveniente de videiras conduzidas no sistema lira aberta. Ciência e Tecnologia de Alimentos, v. 26, n. 2, p. 290-296, 2006. http://dx.doi.org/10.1590/S0101-20612006000200010.

SCHVAB, M.C. et al. Effects of orange winemaking variables on antioxidant activity and bioactive compounds. Food Science and Technology, v. 35, n. 3, p. 407-413, 2015. http://dx.doi.org/10.1590/1678-457X.6571.

MATTOS, J. R. Uvalheira: fruteiras nativas do Brasil. Porto Alegre: Instituto de Pesquisas de Recursos Naturais e Renováveis, 1988. 36 p.

MCRAE, J. M. et al. Effect of wine $\mathrm{pH}$ and bottle closure on tannins. Journal of Agricultural and Food Chemistry, v. 61, n. 47, p. 11618-11627, 2013. http://dx.doi.org/10.1021/jf403704f.

OLEJAR, K. J. et al. Characterization of an antioxidant and antimicrobial extract from cool climate, white grape marc. Antioxidants, v. 8, n. 232, p. 1-13, 2019. http://dx.doi.org/10.3390/antiox8070232.

OLIVEIRA, L. A. et al. Elaboração de bebida fermentada utilizando calda residual da desidratação osmótica de abacaxi (Ananas comosus L.). Revista Brasileira de

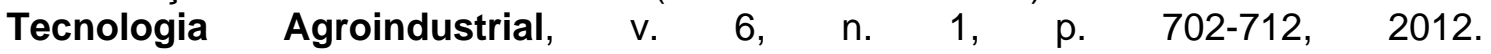
http://dx.doi.org/10.3895/S1981-36862012000100009.

OLIVEIRA, L. A. et al. Aproveitamento da calda residual da cristalização de jaca (Artocarpus heterophyllus Lam.) para elaboração de bebida fermentada. Magistra, v. 25, n. 2, p.157-163, 2013.

PADILHA, C. V. S. et al. Rapid determination of flavonoids and phenolic acids in grape juices and wines by RP-HPLC/DAD: Method validation and characterization of commercial products of the new Brazilian varieties of grape. Food Chemistry, v. 228, p. 106-115, 2017. http://dx.doi.org/10.1016/j.foodchem.2017.01.137. 
PAZ, M. F. et al. Produção e caracterização do fermentado alcoólico de actinidia deliciosa variedade Bruno produzido em Santa Catarina. In: XVI SIMPÓSIO NACIONAL DE BIOPROCESSOS, 29 de julho a $1^{\circ}$ de Agosto, 2011. Anais... Curitiba: Sinaferm, 2007. v. CD. p. PFE0088.

PIRES, C. R. F. et al. Avaliação cromática e perfil de aminas bioativas do fermentado alcoólico de amora-preta. Revista Brasileira de Produtos Agroindustriais, v. 18, n. 1, p. 21-30, 2016. Disponível em: https://vdocuments.mx/avaliacao-cromatica-e-perfilde-aminas-bioativas-deagufcgedubrrbparev181.html. Acesso em 27 dez 2020.

RABELO S. C. V.; BRAGA C. J. M. Análise sensorial de vinhos brasileiros da casta Marcelan por métodos científicos. Revista de Nutrição e Vigilância em Saúde, v. 4, n. 2, p. 6-17, 2017. Disponível em: https://docplayer.com.br/168787330-Analisesensorial-de-vinhos-brasileiros-da-casta-marcelan-por-metodos-cientificos.html.

Acesso em 27 dez 2020.

RIBEIRO, A. E. C.; ASCHERI, D. P. R.; ASCHERI, J. L. R. Aplicação da metodologia de superfície de resposta para a seleção de uma bebida alcoólica fermentada de polpa de baru. Revista Agrotecnologia, v. 2, n. 1, p. 57-72, 2011. http://dx.doi.org/10.12971/2179-5959.v02n01a05.

RIZZON, L. A.; DALL'AGNOL, I. Vinho tinto. 1.ed. Brasília: Embrapa Informação Tecnológica, 2007. 45 p.

RIZZON, L. A.; ZANUS, M. C.; MANFREDINI, S. Como elaborar vinho de qualidade na pequena propriedade. Bento Gonçalves: Embrapa Uva e Vinho, 1994. 36p.

ROSA, C. I. L. F. et al. Pós-colheita e comercialização. In: BRANDÃO FILHO, José Usan Torres et al. (comps). Hortaliças-fruto [online]. Maringá: EDUEM, 2018. p. 489526.

SGANZERLA, W. G. et al. Nutritional, physicochemical and antimicrobial properties of uvaia pulp (Eugenia pyriformis Cambess). Communications in Plant Sciences, v. 8, p. 1-7, 2018. http://dx.doi.org/ 10.26814/cps2018001.

SILVA, T. G. et al. Diagnóstico vinícola do sul de Minas Gerais - Caracterização físicoquímica dos vinhos. Ciência Agrotécnica, v. 23, n. 3, p. 623-637, 1999.

SILVA, D. J.; QUEIROZ, A. C. de. Análise de alimentos: métodos químicos e biológicos. Viçosa: UFV, Imprensa Universitária, 2002. 239 p.

SILVA, N. A. et al. Phenolic compounds and carotenoids from four fruits native from the brazilian atlantic forest. Journal of Agricultural and Food Chemistry, v. 62, p. 50725084, 2014. https://doi.org/10.1021/jf501211p.

SILVA, A. P. G. et al. Characteristics of the fruits of two uvaia populations grown in Salesópolis, SP, Brazil. Rev. Bras. Frutic., Jaboticabal, v. 40, n. 2: (e-511), 2018. https://doi.org/10.1590/0100-29452018511.

SINGLETON, V. L.; ROSSI, J. A. Colorimetry of total phenolics with phosphomolybidicphosphotungstic acid reagents. American Journal of Enology and Viticulture, v. 16, p. 144-158, 1965. Disponível em: https://www.ajevonline.org/content/16/3/144. Acesso em 27 dez 2020. 
SMITH, P. A.; MCRAE, J. M.; BINDON, K. A. Impact of winemaking practices on the concentration and composition of tannins in red wine. Australian Journal of Grape and Wine Research, v. 21, p. 601-614, 2015. https://doi.org/10.1111/ajgw.12188.

SUN, J. et al. Antioxidant and antiproliferative activities of common fruits Journal of Agricultural and Food Chemistry, v. 50, p. 7449 - 7454, 2002. https://doi.org/10.1021/jf0207530.

VOGT, Ernst. La fabricacion de vinos. Zaragoza: Acribia, 1972. 292 p.

ZARDO, D. M. et al. Intensidade de pigmentação vermelha em maçãs e sua relação com os teores de compostos fenólicos e capacidade antioxidativa. Ciência e Tecnologia de Alimentos, v. 29, n. 1, p.148-154, 2009. https://doi.org/10.1590/S010120612009000100023.

ZOECKLEIN, B. W. et al. Wine analysis and production. New York: Kluwer Academic/Plenum Publishers, 1999. 621 p. https://doi.org/10.1007/978-1-4757-6967-8.

\section{Agradecimentos}

Ao Instituto Federal do Triângulo Mineiro, Campus Uberaba e à Universidade Federal de Pelotas que viabilizaram a execução desse trabalho.

\section{Autores}

Luciene Lacerda Costa ${ }^{1,2, *}$, Luiza Vilela ${ }^{2}$, Maxwel Suzigan Gomide ${ }^{2}$, Pedro Henrique Ferreira Tomé ${ }^{3}$, Edson José Fragiorge ${ }^{3}$, Márcia Arocha Gularte ${ }^{4}$

1. Curso de Pós-graduação Lato Sensu em Ciência dos Alimentos, Centro de Ciências Químicas, Farmacêuticas e de Alimentos, Universidade Federal de Pelotas, Campus Universitário, Caixa Postal, 354, 96010-900, Pelotas, RS, Brasil; Laboratório de Bromatologia, Instituto Federal de Educação, Ciência e Tecnologia do Triângulo Mineiro, Endereço: R. João Batista Ribeiro, 4000 - Distrito Industrial I, 38064-790, Uberaba, Brasil.

2. Laboratório de Bromatologia, Instituto Federal de Educação, Ciência e Tecnologia do Triângulo Mineiro, Endereço: R. João Batista Ribeiro, 4000 - Distrito Industrial I, 38064-790, Uberaba, Brasil.

3. Departamento de Físico-química e Bioquímica, Instituto Federal de Educação, Ciência e Tecnologia do Triângulo Mineiro, Endereço: Fazenda Sobradinho s/no Zona Rural, 38400-970, Uberlândia, Brasil.

4. Centro de Ciências Químicas, Farmacêuticas e de Alimentos, Universidade Federal de Pelotas, Campus Universitário, Caixa Postal, 354, 96010-900, Pelotas, RS, Brasil.

* Autor para correspondência: luciene@iftm.edu.br 